\title{
LABORATORIO
}

\section{Implementación de la técnica de PCR en la identificación de Babesia ssp en equinos}

\author{
DANILO VARGAS*, RAFAEL BONET*, PAULINA OLIVA* y SERGIO CAMPANO**
}

\section{IMPLEMENTATION OF PCR TECHNIQUE IN THE EQUINE IDENTIFICATION OF Babesia ssp.}

Babesia equi and Babesia caballi are intraerythrocytic protozoan parasites transmitted by ticks, causing equine babesiosis. Although the reference techniques recommended by USDA and OIE are IFAT and CF, they yields falsenegative results and don't let differentiate between babesia's species. The implementation of polymerase chain reaction $(P C R)$ as a direct technique for the identification and characterization of these parasites, without doubt enrich the clinical diagnosis of babesiosis. . For all those reasons in the present report was estandarizated PCR for the identification of $\boldsymbol{B}$. equi and $\boldsymbol{B}$. caballi. The proceeding included blood DNA extraction protocol and the PCR optimization for the reaction mix and the termocyclig program, with four primers asigned $P 1$ and $P 2$ for $B$. equi and P3 and $P 4$ for B. caballi. Both amplified in a selective way a conserved regions from the 16S rRNA genes ( $r D N A)$ of $659 \mathrm{bp}$ for $\boldsymbol{B}$. equi and $664 \mathrm{bp}$ for B. caballi. The minimal amount of DNA detected from positives controls was $0,1 \mathrm{ng} / \mu \mathrm{l}$ for $\boldsymbol{B}$. equi and $1 \mathrm{ng} / \mu \mathrm{l}$ for $\boldsymbol{B}$. caballi. The primer set chosen do not produced amplifications fragments using others DNAs, like Toxoplasma gondii, Trypanosoma cruzi, Echinococcus granulosus, Fasciola hepatica. 77 horse blood specimens from Metropolitan Region, were tested for B. equi and B. caballi by PCR, 62 samples were negatives and 15 positives (14 to $\boldsymbol{B}$. equi and 1 to $\boldsymbol{B}$. caballi). With the aim of developing epidemiological studies, comparison PCR and microscopy, we are testing horse blood samples with suspicious of babesiosis.

Key words: Babesia equi, Babesia caballi, Diagnosis, Protozoa, PCR.

\section{INTRODUCCIÓN}

Piroplasmosis o babesiosis equina es una enfermedad producida por protozoos del género Babesia; Babesia equi y Babesia caballi. Ambos parásitos se ubican en glóbulos rojos ${ }^{1}$ y linfocitos ${ }^{2}$ de caballos, mulas, burros, cebras, y son transmitidos por garrapatas del género Dermacentor y Rhipicephalus entre otras) ${ }^{3}$. Según la gravedad de la infección, el daño se manifiesta desde una disminución en el rendimiento físico hasta la muerte del animal ${ }^{4}$.

La piroplasmosis equina presenta una amplia distribución y diversas características epidemiológicas según la localización geográfica. Los equidos de biomas tropicales y subtropicales están constantemente expuestos al agente patógeno, desarrollando una respuesta inmune activa.

En Chile, esta patología también está presente ${ }^{5}$, su manifestación clínica es moderada

\footnotetext{
* Laboratorio de Diagnóstico Molecular DIAMOLAB®. Universidad Mayor. Casilla 234, Correo 35. Las Condes, Santiago, Chile.Email: dvargas@email.umayor.cldiamolab@email.umayor.cl

** Laboratorio de Parasitología. Servicio Agrícola y Ganadero Lo Aguirre.
} 
a leve y generalmente pasa desapercibida ${ }^{1}$, con una prevalencia estimada en $2,2 \%{ }^{6}$. Los problemas indirectos que ocasionan involucran menor rendimiento deportivo e impedimento de competir en torneos internacionales ${ }^{7}$.

En la actualidad existen diversos métodos directos para el diagnóstico de la infección tales como el frotis sanguíneo la inoculación experimental. Sin embargo, éstos están sujetos a la experiencia y criterio del profesional que los ejecuta. Entre los métodos indirectos más usados, existen varias pruebas serológicas como, fijación del complemento, fluorescencia indirecta y ELISA $^{8}$, cuyos resultados varían según el nivel de anticuerpos en la sangre del hospedero al momento de extraer la muestra; Además la diferenciación por signos y síntomas no es posible, ya que para ambas infecciones se debe realizar un diagnóstico diferencial con Anemia infecciosa equina y Hepatopatías ${ }^{1}$.

Lo anteriormente expuesto, justifica la necesidad de una técnica que permita la identificación directa, rápida, específica y sensible, capaz de diferenciar el parásito en los equinos. Con este propósito el presente trabajo, basado en los estudios de otros investigadores, evaluó la implementación y aplicación de la técnica de PCR, utilizando partidores que amplifican en forma selectiva una secuencia conservada de los genes de $16 \mathrm{SrDNA}$ de $B$. equi y $B$. caballi, con tamaños moleculares de 659 y 664 pb, respectivamente. El trabajo fue financiado por el Proyecto del Fondo de Investigación de la Universidad Mayor titulado: "Marcadores genéticos asociados a producción animal"

\section{MATERIAL Y MÉTODOS}

1.- Material Biológico: El DNA de los parásitos fue obtenido a partir de extractos biológicos obtenidos de muestras de sangre de equinos con infección confirmada y proporcionadas por el Servicio Agrícola y Ganadero (SAG) de Chile.

Se estudiaron 77 muestras de sangre de equinos procedentes de la Región Metropolitana, con y sin sospecha clínica a la infección. Las muestras positivas a PCR se confirmaron por visualización microscópica de los merozoítos en sangre por Tinción Giemsa ${ }^{10}$.

2.- Extracción DNA. La extracción de DNA a partir de muestras de sangre, se realizó por "shock" hiposmótico e incubación con
Proteinasa K, Sarcosina y SDS $^{9}$. Posteriormente, las muestras se trataron con solventes orgánicos (Fenol-cloroformo) y los ácidos nucleicos fueron precipitados con etanol y acetato de sodio. Finalmente, el material genético se suspendió en solución tampón TE (Tris 10 mM-EDTA $1 \mathrm{mM}$ ) y cuantificado espectrofotométricamente ${ }^{11}$.

3.- PCR. La estandarización de PCR se basó según lo descrito por Bashiruddin 1999 ${ }^{9}$, con algunas modificaciones. La mezcla de reacción se realizó en un volumen final de $50 \mu$ l, utilizando solución tampón de amplificación 10X $(200 \mu \mathrm{M}$ Tris $\mathrm{HCl}$, $500 \mu \mathrm{M} \mathrm{KCl} \mathrm{pH} \mathrm{8,4)} \mathrm{(Gibco} \mathrm{BLR),} 2 \mu \mathrm{M} \mathrm{MgCl}_{2}$, $0,2 \mu \mathrm{M}$ de dNTPs, $0,2 \mu \mathrm{M}$ de partidores para $B$. equi y $1 \mu \mathrm{M}$ para los de $B$. caballi, $5 \mathrm{ng} / \mathrm{ml}$ de DNA blanco, 2 UI Taq DNA Polimerasa (Gibco BLR).

El programa de termociclación asignado como BF- 1 constó de $94^{\circ} \mathrm{C}$ por 5 minutos; 30 ciclos de: $94^{\circ} \mathrm{C}$ por 30 segundos, $55^{\circ} \mathrm{C}$ por 30 segundos, $72^{\circ} \mathrm{C}$ por 30 segundos, seguido de $72^{\circ} \mathrm{C}$ por 5 minutos.

La resolución de los fragmentos amplificados por PCR se realizó por electroforesis horizontal en geles de agarosa al 1\% (p/v) en solución tampón de corrida TBE $(0,09 \mathrm{M}$ Tris-Borato, 0,002 M EDTA) y teñidos con bromuro de etidio al $0,005 \%$ (v/v). La electroforesis se realizó a un voltaje constante de 10 volt $/ \mathrm{cm}$. Se utilizó como indicador de peso molecular Ladder de $100 \mathrm{pb}$ (Gibco BLR). La observación de los fragmentos amplificados se efectuó a través de un transiluminador de luz UV (Vilber Lourmar, 50 watts). Los resultados obtenidos se registraron en fotografías Polaroid, hasta su análisis.

4.- Validación técnica de la PCR. La validación de PCR contempló un estudio de sensibilidad técnica, para determinar la concentración mínima de DNA susceptible de amplificar y un estudio de especificidad técnica, para lo cual se ensayaron los partidores señalados con DNAs de: Toxoplasma gondii, Trypanosoma cruzi, Echinococcus granulosus, Fasciola hepatica.

\section{RESULTADOS}

La Figura 1, muestra los resultados de la estandarización de la mezcla de reacción para $B$. equi (A) y B. caballi (B) Se ensayaron diferentes concentraciones de los reactivos de la mezcla de reacción. Para B. equi (carril 3) y para B. caballi (carril 7), se observó un amplicón caracterizado 


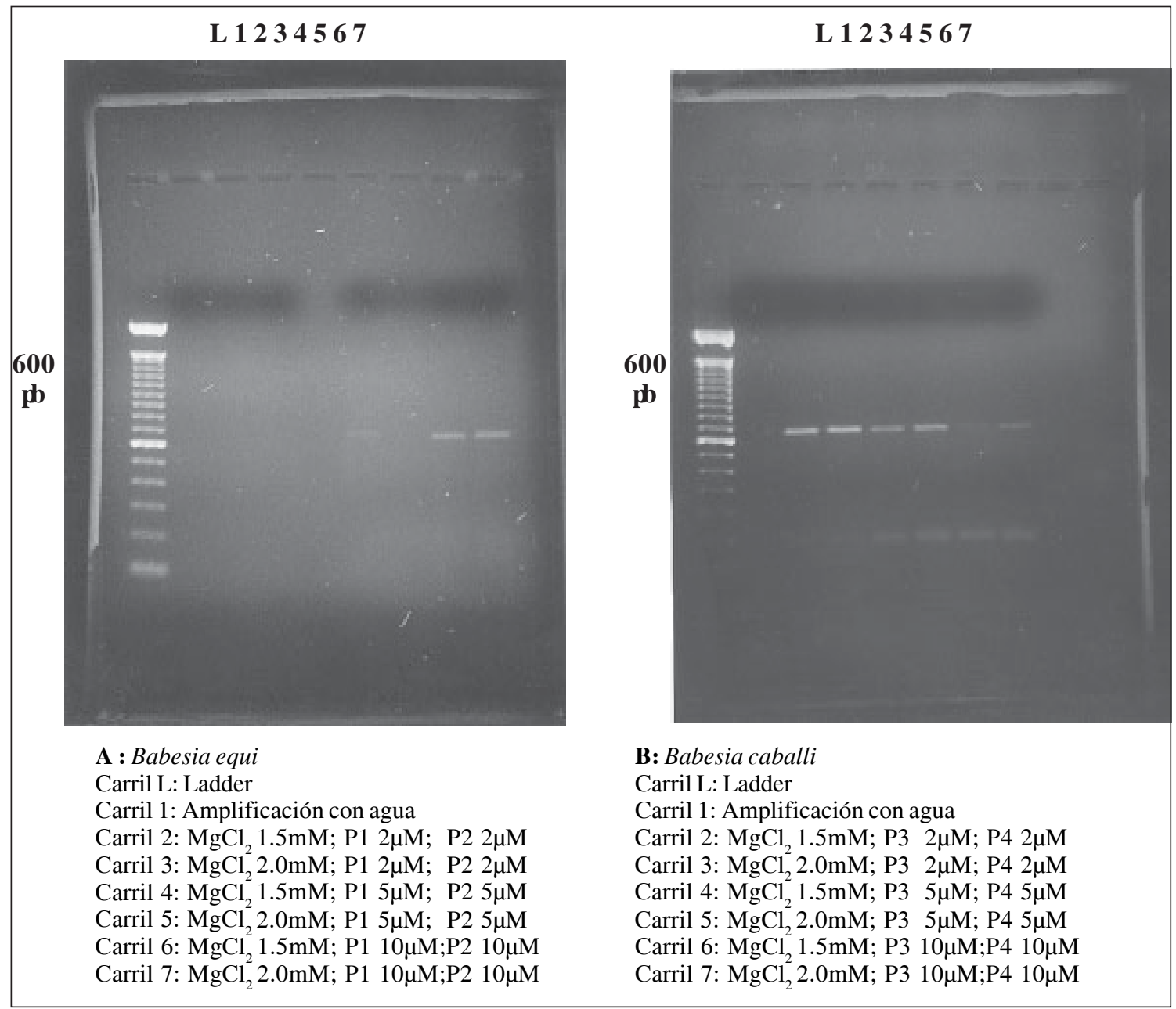

Figura 1. Estandarización de PCR en la identificación de Babesia equi y Babesia caballi.

por una migración de 620 bp (p: 0,05), reproducibilidad en los ensayos y ausencia de fragmentos amplificados inespecíficos.

La validación técnica de PCR en la identificación de B. equi y B. caballi, contempló estudios de Sensibilidad y Especificidad técnicas. La concentración mínima de DNA posible de amplificar por PCR, para B. equi correspondió a $100 \mathrm{pg}$ y para B. caballi fue de $1 \mathrm{ng}$.

La aplicación de PCR a una población piloto identificó infección por Babesia sp en 15 (19,5\%) de las muestras en estudio, de las cuales 14 corresponden a B. equi y 1 a B. caballi. Estudios que se corroboraron por Tinción de Giemsa.

\section{DISCUSIÓN}

El protocolo aplicado en la extracción de DNA fue satisfactorio, obteniéndose concentraciones promedio de $44,25 \mathrm{ng}$, resultados que son corroborados por otros investigadores?.

Los partidores seleccionados fueron altamente específicos en el reconocimiento de secuencia de DNA de B. equi y B. caballi. Los cuales se caracterizaron por amplificar regiones del DNA que permiten mayor estabilidad estructural y escasas variaciones intraespecíficas ${ }^{12}$.

El programa de termociclación propuesto por Bashiruddin et $\mathrm{al}^{9}$, permitió amplificar en forma 
simultanea a $B$. equi y B. caballi, otorgando operatividad en la identificación de la especie infectante. La reproducibilidad del estudio se evidenció con los resultados obtenidos al analizar muestras por duplicado en termociclaciones diferentes, lo cual también coincide con estos autores ${ }^{9}$.

La PCR se presenta como una excelente alternativa técnica de referencia y complementaria a la serología en los estudios de seguimiento y/o evolución de los tratamientos efectuados en los animales infectados.

Sin duda, la información certera y válida que proporciona esta metodología, propone una validación epidemiológica de la misma, de esta manera contribuir al estado sanitario de la población equina en nuestro país y fortalecer líneas de acción para el control y prevención de la enfermedad. Actualmente, está en proceso una investigación que ensaya por PCR muestras de sangre con sospecha clínica y serológica.

\section{RESUMEN}

Aunque las técnicas de referencias citadas por la USDA y OIE son IFI y FC, para el diagnóstico de las infecciones por Babesia equi y Babesia caballi, éstas no permite la diferenciación entre las especies y no descartan resultados falsos negativos. La implementación de la PCR como técnica directa, en la identificación y carac-terización de estos parásitos, sin duda constituye un soporte al diagnóstico clínico de la piroplasmosis equina.

Dado lo anteriormente expuesto en el presente trabajo se estandarizó la PCR para la identificación de $B$. equi y $B$. caballi. El procedimiento contempló la implementación de un protocolo de extracción de DNA, a partir de muestras de sangre y la optimización de PCR, tanto para la mezcla de reacción como para el programa de termociclación, junto a 4 partidores: P1 y $\mathrm{P} 2$ para $B$ equi y $\mathrm{P} 3$ y $\mathrm{P} 4$ para $B$ caballi. Ambos amplifican en forma selectiva una secuencia conservada de los genes de $16 \mathrm{~S}$ rDNA, equivalentes a 659 bp para B. caballi y 664 bp para B. equi. La sensibilidad técnica fue de $0,1 \mathrm{ng} /$ $\mu \mathrm{l}$ para B. equi y $1 \mathrm{ng} / \mu \mathrm{l}$ para $B$. caballi. El estudio de especificidad técnica no mostró productos de amplificación al utilizar DNAs de Toxoplasma gondii, Trypanosoma cruzi, Echinococcus granulosus, Fasciola hepatica.

Se estudiaron 77 muestras de sangre de equinos provenientes de la Región Metropolitana de Chile con y sin sospecha clínica, de las cuales 15 resultaron positivas (14 a B. equi y 1 a $B$. caballi).

Nuestros resultados crearon la necesidad de una evaluación epidemiológica de la PCR y su confrontación con otras técnicas de diagnóstico directo, para lo cual en la actualidad se estudian muestras de sangre equina con sospecha a piroplasmosis,

\section{REFERENCIAS}

1.- CAMPANO S. Detección de piroplasmosis equina producida por Babesia equi (Apicomplexa: Babesiidae) mediante inmunodifusion en agar gel (IDAG). Bol. Epizoot. SAG Ministerio de Agricultura Chile 1991. 2 (2).

2.- MEHLHORN H. Manual de Parasitología Veterinaria Bogotá. Grass-Iatros 1993.

3.- BORCHERT A. Parasitología Veterinaria. $3^{\circ}$ Edición, Ed. Acribia. 1981.

4.- SOULSBY E J L. Parasitología y enfermedades parasitarias en los animales domésticos, $7^{\mathrm{a}}$ Edición Ed. Interamericana. 1988. pp. 719-35.

5- RUDOLPH W. Piroplasmosis en caballos de carrera de Chile. Bol Chil Parasitol 1971; 26: 66-8.

6.- CAMPANO S, MORENO P, MUÑOZ C. Piroplasmosis Equina: Análisis de Diagnósticos efectuados entre 1984 y 1996. Bol. Epizoot. SAG Ministerio de Agricultura Chile 1997; 6 (1).

7.- CONFERENCE: EQUINE INFECTED DISEASE (CONF.EQ.INF.DISEASE) $\left(8^{\text {th }}, \quad\right.$ Nov., 1998) Piroplasmosis [en línea] [http://A: piroplasmosis.htm] [Consulta 18 Enero 2004].

8.- ERNST N, ERNST S, MONTES G, URCELAY S. Piroplasmosis Equina: Estudio serológico en el Club Hípico de Santiago, Chile. XI Congreso Nacional de Medicina Veterinaria. Santiago, Chile 1999.

9.- BASHIRUDDIN J B, CAMMA C, REBELO O E, Molecular detection of Babesia equi y Babesia caballi in horse blood by PCR amplification of part of the $16 \mathrm{~S}$ rRNA gene. Vet Parasitol 1999; 84: 75-83.

10.- BOTTEON P de T L, MASSARD C I, BOTTEON R de $\mathrm{C}$ C M et al. Seroprevalencia de Babesia equi en tres diferentes sistemas de crianza de equinos: Rio de Janeiro - Brasil. Parasitol Latinoam 2002; 57: 141-5.

11- SAMBROOK J, FRITSCH E F, MANIATIS T. Molecular Cloning. A laboratory Manual $2^{a}$ Edition. Cold Spring Harbor Laboratory Press. 1989.

12- ELLIS J, HELFORD C, BAVERSTOCH P R. Ribosamel DNA sequence comparision of Babaesia and Theileria. Mol Biochem Parasitol 1992; 54: 87-96. 